\title{
Bursting Induces Persistent All-or-None EPSPs by an NMDA-Dependent Process in Piriform Cortex
}

\author{
William H. Hoffman' ${ }^{1}$ and Lewis B. Haberly ${ }^{1,2}$ \\ 'Neurosciences Training Program and 'Department of Anatomy, University of Wisconsin, Madison, Wisconsin 53706
}

\begin{abstract}
Burst responses to stimulation of excitatory fiber tracts in olfactory cortex slices after removal of extracellular $\mathbf{M g}^{2+}$ or decreases in extracellular $\mathrm{Cl}^{-}$, resulted in long-lasting changes in response properties of neurons following a return to normal bathing medium. After bursting activity, the response of pyramidal cells to stimulation of afferent or associational fiber systems consisted of the normal graded depolarizing postsynaptic potential and a new, high-amplitude depolarizing potential that followed the graded potential at a variable latency. The new late potential had a waveform that resembled the initial graded response, but it occurred in an all-or-none fashion with a discrete threshold and persisted for many hours. Threshold for the late potential was similar for different cells in the same slice and was not affected by intracellular current injection, indicating that a synchronized interaction among a large number of cells is involved in its generation. Properties of the late potential indicate that it is an EPSP. NMDA receptor antagonists (APV and ketamine) had little effect on the late potential but prevented its development if present during bursting activity. The possible relevance of these findings to the study of the neuronal substrate for long-term memory and epilepsy is discussed.
\end{abstract}

Synchronous activation of fiber tracts by shock stimulation can induce long-lasting changes in response properties of neurons (McNamara et al., 1980; Teyler and DiScenna, 1987). These changes are being explored for possible roles in learning and memory, as wcll as epileptogenesis. While most studies of this type have been carried out on the hippocampus, the olfactory cortex has similar structural features that make it well-suited for physiological analysis and modeling. These features include a relatively simple structure that has been comparatively wellcharacterized and a laminar segregation of fiber systems, somata of different neuron types, and dendritic elements of pyramidal cells (Haberly, 1985). In recent years there has been increasing interest in the olfactory cortex for the development of models for learning and memory (e.g., Grossberg, 1976; Freeman and Schneider, 1982; Haberly, 1985; Lynch, 1986; Wilson and Bower, 1987) and for analysis of neuronal mechanisms that underlie kindling and pharmacologically induced epilepsy (e.g., McIntyre

\footnotetext{
Received Mar. 3, 1988; revised May 31, 1988; accepted June 1, 1988.

We thank Drs. Peter I ipton, Donata Dertel, and Thomas Sutula for their helpful comments on the manuscript. This work was supported by Grant NS19865 from the NINCDS (L.B.H.) and training grant GMO7507 (W.H.H.).

Correspondence should be addressed to Lewis B. Haberly, Department of Anatomy, University of Wisconsin, 1300 University Avenue, Madison, WI 53706.

Copyright (C) 1989 Society for Neuroscience $0270-6474 / 89 / 010206-10 \$ 02.00 / 0$
}

et al., 1982; Kairiss et al., 1984; Piredda and Gale, 1985; McIntyre and Racine, 1986; McIntyre and Wong, 1986; Millan et al., 1986).

We report here that fiber tract stimulation in vitro, after ionic or pharmacological manipulations that evoke bursting activity, results in the appearance of a long-latency depolarizing potential, not present in control responses, that can persist for the duration of experiments. Development of the bursting-induced late potential is dependent upon activation of NMDA receptors. Identification of the long-lasting plastic changes that underlie the late potential and the mechanism of their induction may be relevant to understanding the neural substrate of learning and memory. In addition, because of similarities to changes induced by kindling in vivo (Sutula and Haberly, 1986), the present preparation is a potential in vitro model for kindling and epileptogenesis.

\section{Materials and Methods}

General methods for slice preparation and recording have previously been described in detail (Tseng and Haberly, 1988a). In brief, etheranesthetized rats were decapitated, a block of brain containing piriform cortex was removed, and slices $500 \mu \mathrm{m}$ thick were cut perpendicular to the cortical surface with a Vibratome (Oxford) in oxygenated artificial cerebrospinal fluid (ACSF) at $4-10^{\circ} \mathrm{C}$. Slices were allowed to recover for a minimum of $2 \mathrm{hr}$ in oxygenated ACSF at room temperature. Recordings were laken from submerged slices continuously perfused with ACSF at $27-30^{\circ} \mathrm{C}$ in the chamber described by Tseng and Haberly (1988a). The ACSF consisted of (mM) $124.0 \mathrm{NaCl}, 5.0 \mathrm{KCl}, 2.4 \mathrm{CaCl}_{2}$, 1.3 $\mathrm{MgSO}_{4}, 26.0 \mathrm{NaHCO}_{3}, 1.2 \mathrm{KH}_{2} \mathrm{PO}_{4}$, and 10.0 D-glucose, equilibrated with $95 \% \mathrm{O}_{2}-5 \% \mathrm{CO}_{2}$. In some experiments, $\mathrm{Na}_{2} \mathrm{SO}_{4}$ was substituted for $\mathrm{MgSO}_{4}$ (referred to below as $0 \mathrm{Mg}^{2+} \mathrm{ACSF}$ ); in others, 50 , 90 , or $93 \%$ of $\mathrm{Cl}^{-}$was replaced with isethionate (referred to below as low-CL- ACSF). Intracellular recordings were made from pyramidal cells in layer II (compact cell body layer) (Fig. 1), identified as previously described (Haberly and Bower, 1984; Tseng and Haberly, 1988a). Micropipettes were filled with $4 \mathrm{M}$ potassium acetate; tip resistances were 40-90 M $\Omega$. Current was injected intracellularly with a bridge circuit (WPI M707). Bipolar tungsten microelectrodes were used to stimulate pyramidal cell association fibers in layer Ib or, occasionally, lateral olfactory tract afferents in layer Ia at $1 / 6 \mathrm{~Hz}$ (Fig. 1). Shock strengths were typically $20-50 \%$ of the strength evoking a maximal response. Responses were digitized, stored on high-capacity disk cartridges, and analyzed by computer as described previously (Tseng and Haberly, 1988a). Drugs were bath-applied; D,L-2-amino-5-phosphonovaleric acid (D,L-APV) and 4-aminopyridine (4-AP) were obtained from Sigma, D-2amino-5-phosphonovaleric acid (D-APV) was obtained from Cambridge Research Biochemicals, and ketamine $\mathrm{HCl}$ was obtained from ParkeDavis.

\section{Results}

Recordings were made from 148 pyramidal cells in 89 slices. Resting membrane potentials averaged $-75.0 \mathrm{mV}(n=70, \mathrm{SD}$ $=4.1 \mathrm{mV}$ ). The response to stimulation of afferent and association fibers, which has been previously characterized in this 
preparation (Bower and Haberly, 1986; Tseng and Haberly, 1988a), consists of an initial depolarizing potential followed by a late hyperpolarizing potential (LHP) of approximately 600 msec duration (Fig. 2, $A, B$ ). The depolarizing potential consists of a monosynaptic excitatory postsynaptic potential (EPSP) and a partially overlapping, disynaptic, $\mathrm{Cl}^{-}$-mediated inhibitory postsynaptic potential (IPSP) that is depolarizing at resting membrane potential. The $\mathrm{Cl}^{-}$-mediated IPSP becomes hyperpolarizing and can be seen to truncate the EPSP when the cell is depolarized past the $\mathrm{Cl}^{-}$equilibrium potential by current injection (Fig. $2 B$ ). The LHP is a disynaptic IPSP mediated by $\mathrm{K}^{+}$(Fig. 2, $A, B$ ) (Tseng and Haberly, 1988).

\section{Bursting activity in $0 \mathrm{Mg}^{2+}$}

As previously demonstrated in hippocampal cortex (Coan and Collingridge, 1985; Anderson et al., 1986; Walther et al., 1986) and neocortex (Horne et al., 1986; Thomson and West, 1986), burst responses could be induced by removal of $\mathrm{Mg}^{2+}$ from the bathing medium. Burst responses in $0 \mathrm{Mg}^{2+}$ evoked by stimulation of association or afferent fibers consisted of a high-amplitude (10-40 mV), long-duration $(0.5-6 \mathrm{sec})$ depolarizing potential with superimposed action potentials (Fig. $2 C$ ). Spontaneous bursts and smaller depolarizing potentials occurred in the absence of stimulation, but not between burst responses evoked at $1 / 6 \mathrm{~Hz}$. The development of evoked and spontaneous bursting behavior was blocked by APV (below), indicating that such activity resulted from NMDA receptor activation.

\section{Long-lasting changes in response properties after $0 \mathrm{Mg}^{2+}$}

Following a return to normal ACSF after 5-25 min of stimulusinduced bursting in $0 \mathrm{Mg}^{2+}$, there was a striking change in the response to stimulation of association or afferent fibers in comparison with control responses obtained before bursting activity. As illustrated in Figure $2 D$, the post-bursting response consisted of the initial graded depolarization followed by a new, highamplitude depolarizing potential that followed the graded potential. A consistent feature of this late depolarizing potential was the presence of a discrete threshold stimulus strength, below which it was not evoked. Once established in a slice, late depolarizing potentials were observed in all cells impaled and were retained for the remainder of experiments (up to $10 \mathrm{hr}$ ) in 36 of 42 slices. Late potentials of this form were never observed in control slices, even in response to high-strength stimulation of afferent or association fiber systems. A second induction of bursting by stimulation in $0 \mathrm{Mg}^{2+}$ resulted in an increase in amplitude (up to 2 times) and a decrease in threshold (5-15\%) of the late potential after restabilization in normal ACSF $(n=$ 3 ), suggesting that the induction process is graded in nature and may depend upon the intensity or duration of bursting activity.

Latency, amplitude, and duration of the late depolarizing potential were variable in individual trials, especially near threshold (Fig. $2 E$ ), but remained relatively unchanged over long periods of time when averaged over a number of trials at a fixed stimulus strength. Average latency was strongly correlated with stimulus intensity, being maximal at threshold (up to $300 \mathrm{msec}$ ) and decreasing with increasing stimulus strength (Fig. 3). The average amplitude of the late potential appeared to be independent of stimulus strength, except at higher strengths, where amplitude decreased when overlap occurred with the initial graded potential. Because of the lack of dependence of amplitude on stimulus strength and the presence of a discrete threshold, the

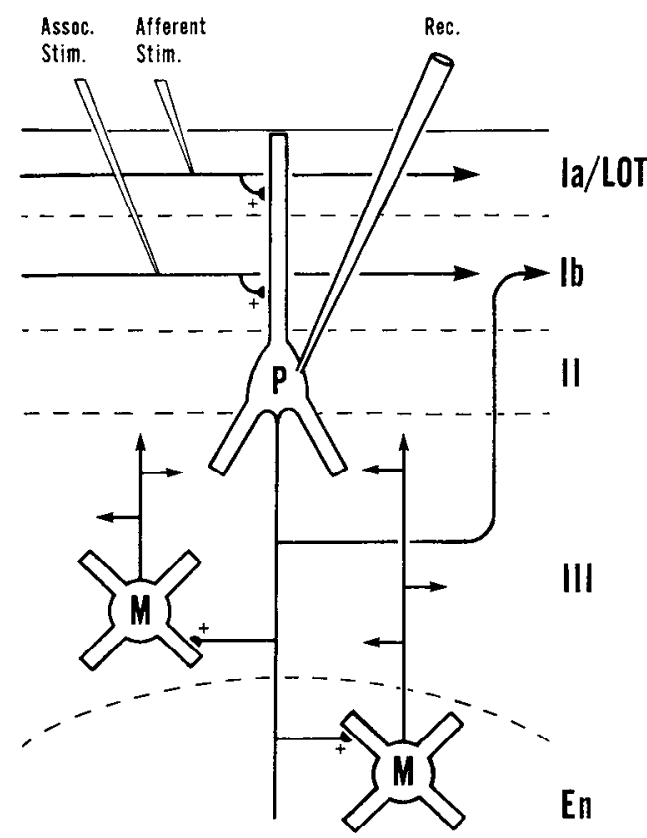

Figure 1. Schematic diagram of piriform cortex showing layers, positions of electrodes, and relevant neuronal circuitry. Potentials were recorded intracellularly from pyramidal $(P)$ cells in layer II (compact cell body layer equivalent to stratum pyramidale of hippocampus) in response to stimulation of intrinsic association fibers in layer $I b$ or afferent fibers from the olfactory bulb in layer Ia or the overlying lateral olfactory tract $(L O T)$. Deep multipolar $(M)$ cells in layer III (equivalent to stratum oriens of the hippocampus) and the subjacent endopiriform nucleus $(E n)$ that are believed to be involved in the changes induced by bursting activity are also illustrated.

late potential can be said to be all-or-none in character, despite the presence of variability in amplitude and waveform on successive trials.

Plots of threshold for the late potential $(n=6)$ revealed only small variations over periods of $0.5-3.5 \mathrm{hr}$. In the cell illustrated in Figure 4, for example, average threshold was constant within $\pm 0.2 \mathrm{~V}$ over a period of more than $3 \mathrm{hr}$ (before the experiment was terminated) following an initial 5-10 min stabilization pcriod after return to normal ACSF. In some cells there appeared to be a small, but progressive increase in threshold over a comparable period. Threshold also increased following continuous, suprathreshold stimulation $(1 / 6 \mathrm{~Hz})$ but returned to its former stable level after a brief period of subthreshold stimulation.

A question of central importance in determining the mechanism of generation of the late depolarizing potential is whether the potential is endogenously mediated in individual cells or synaptically mediated. Alteration of the somatic membrane potential of individual impaled cells over the range -15 to -140 $\mathrm{mV}$ had no detectable effect on the threshold stimulus strength $(n=3)$. Moreover, all cells tested in a given slice had similar thresholds for the late potential ( $n=3$ slices) (Table 1), while thresholds for cells in different slices varied over a wide range $(0.5-10 \mathrm{~V})$. These observations indicate that the late potential is generated as a consequence of a synchronous interaction among large numbers of cells, and is not an endogenous potential evoked independently in individual pyramidal cells. Failure of highamplitude depolarizing current pulses delivered to individual pyramidal cells to evoke late potentials or bursting activity strengthens this conclusion.

When the amplitude of the late potential was sufficiently high, 

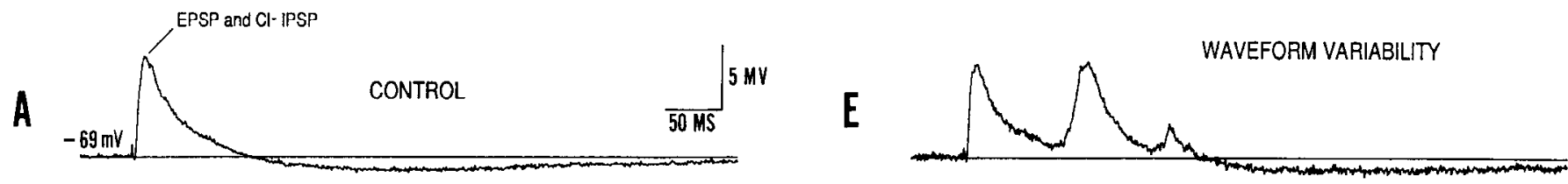

B
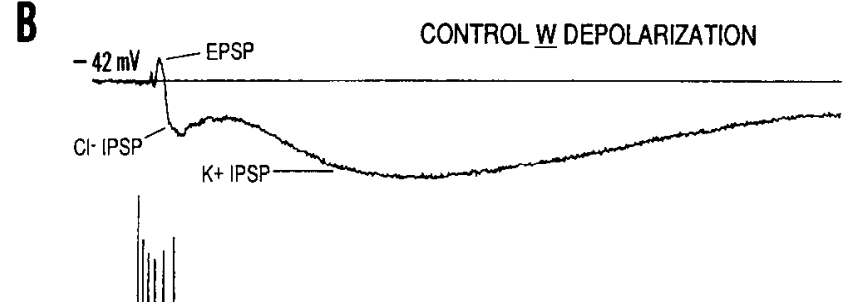

OMg2+ BATHING MEDIUM
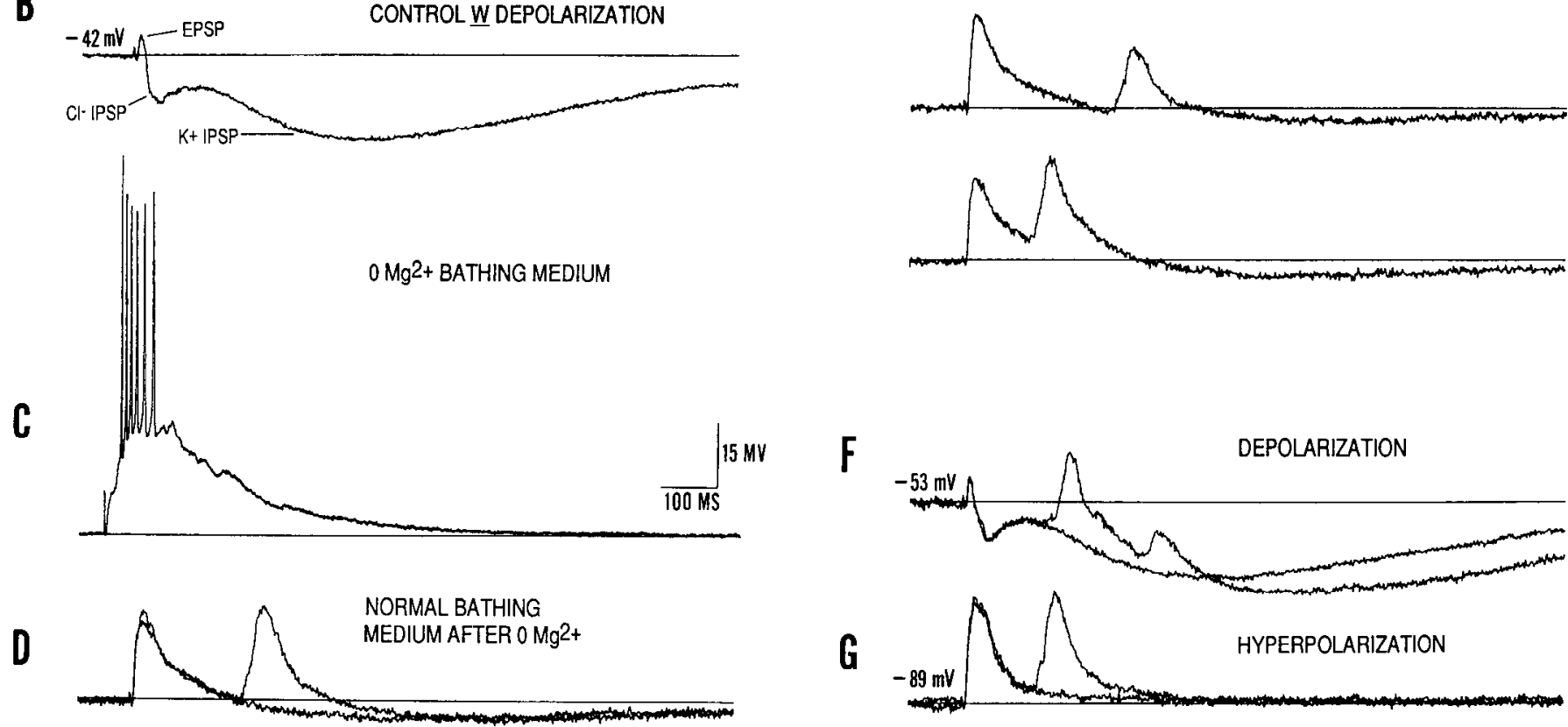

Figure 2. Response properties of layer II pyramidal cells and changes following bursting activity. All traces are from the same cell in response to identical 3.0 V shocks to association fibers in layer Ib, except $C$, where shock strength was $6.0 \mathrm{~V}$. $A$, Control response at resting membrane potential (average of 6 trials). Response consists of an initial graded depolarizing potential (combined monosynaptic EPSP and depolarizing, $\mathrm{Cl}^{-}-$mediated IPSP) and a slow $\mathrm{K}^{+}$-mediated IPSP (see text). $B$, Control response with cell depolarized to $-42 \mathrm{mV}$ by intracellular current injection, showing inversion of the $\mathrm{Cl}^{-}$-mediated IPSP and enhancement of the $\mathrm{K}^{+}$-mediated IPSP (average of 4 trials). $C$, Burst response to stimulation of layer Ib in $0 \mathrm{Mg}^{2+}$ (note change in scale). Response consists of large depolarization evoking action potentials. $D$, Response to association fiber stimulation $32 \mathrm{~min}$ after return to normal bathing medium following bursting activity in $0 \mathrm{Mg}^{2+}$. Note the late depolarizing potential that follows the normal graded depolarizing potential. The all-or-none character of this potential is illustrated by superimposed traces recorded at threshold for its occurrence. $E$, Selected responses to threshold stimuli showing the range of variability in waveform and latency of the late depolarizing potential. $F$, Superimposed traces at threshold stimulus strength as in $D$ but with somatic membrane depolarized by current injection to $-53 \mathrm{mV}$. Note that high-amplitude early and late IPSPs are present (compare with $B$ ). $G$. Same as $F$, but cell hyperpolarized to $-89 \mathrm{mV}$. Scale bars in $A$ apply to all traces except $C$.

action potentials were evoked. Like the monosynaptic EPSP, the late potential did not invert during injection of depolarizing current that reversed the depolarizing, $\mathrm{Cl}^{-}$-mediated IPSP (Fig. $2 F$ ). The amplitude of the late potential decreased with mem-

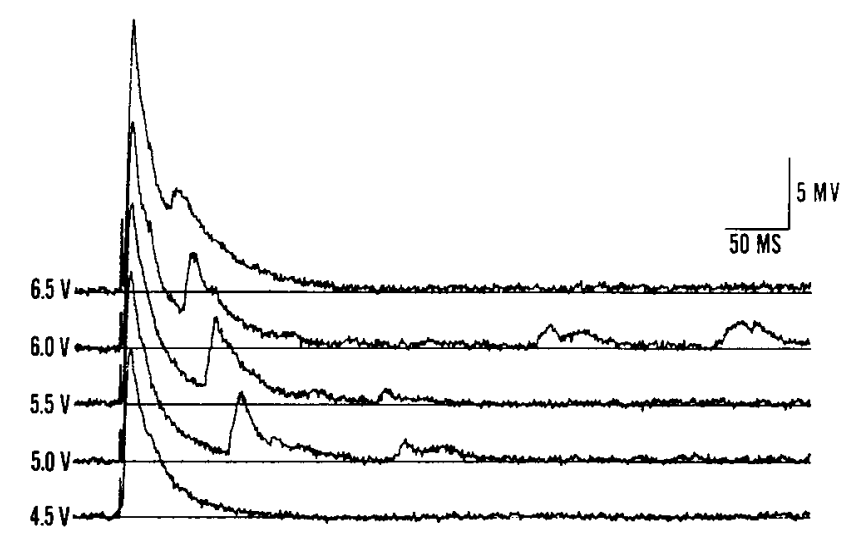

Figure 3. Latency of the late depolarizing potential decreases with increasing stimulus strength. Values at left of baseline indicate stimulus strength for each trial, starting below threshold for the late potential. Note that amplitude of the late potential is independent of stimulus strength when there is no overlap with the initial depolarizing potential.
Table 1. Threshold stimulus strength for the all-or-none depolarizing potential recorded from 13 cells in 1 slice

\begin{tabular}{lcllc}
$\begin{array}{l}\text { Penetra- } \\
\text { tion } \\
\text { number }\end{array}$ & Cell number & $\begin{array}{l}\text { Mean } \\
\text { threshold } \\
\text { stimulus } \\
\text { strength }\end{array}$ & $\begin{array}{l}\text { Number of } \\
\text { threshold } \\
\text { measure- } \\
\text { ments }\end{array}$ & $\begin{array}{l}\text { Time } \\
\text { (min) }\end{array}$ \\
\hline 1 & 1 & 1.3 & 23 & 53 \\
& 2 & 1.3 & 6 & 64 \\
& 3 & 1.3 & 8 & 76 \\
2 & 4 & 1.3 & 2 & 81 \\
& 5 & 1.4 & 11 & 97 \\
3 & 6 & 1.4 & 5 & 106 \\
& 7 & 1.4 & 12 & 123 \\
& 8 & 1.5 & 7 & 132 \\
4 & 9 & 1.4 & 4 & 142 \\
5 & 10 & 1.5 & 1 & 146 \\
6 & 11 & 1.5 & 1 & 149 \\
& 12 & 1.6 & 6 & 158 \\
& 13 & 1.5 & 6 & 171 \\
\hline
\end{tabular}

Penetrations 2-4 were within $400 \mu \mathrm{m}$ of penetration 1; penetrations 5 and 6 were $500-1000 \mu \mathrm{m}$ from penetration 1 . Time zero refers to switch from $0 \mathrm{Mg}^{2+}$ to normal bathing medium. 


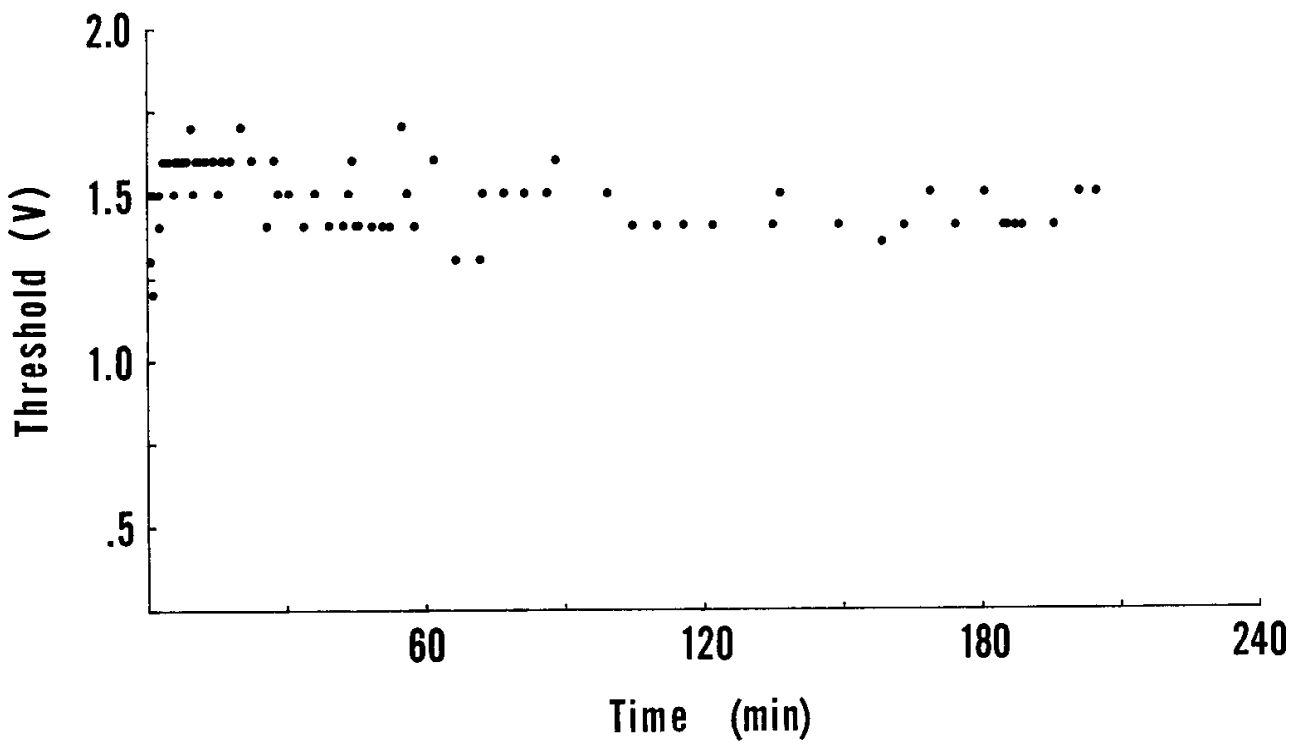

Figure 4. Average threshold for the late depolarizing potential changes little over time following an initial stabilization period. Time zero corresponds to the return to normal bathing medium after repeated burst responses evoked in 0 $\mathrm{Mg}^{2+}$ by association fiber stimulation. Each point was obtained by increasing stimulus strength in $0.1 \mathrm{~V}$ increments until the late potential was observed (stimulus frequency $1 / 6 \mathrm{~Hz}$ ). brane depolarization and incrcascd with hypcrpolarization (Fig. $2, F, G)$. As discussed below, these observations, taken together with the evidence for an interaction among a population of cells, suggest that the late potential is an EPSP and that synchronization of this potential throughout the slice is synaptically mediated.

\section{Effects of late potential induction on properties of layer II pyramidal cells}

To investigate the mechanism of generation of the late potential, membrane properties and synaptically evoked potentials were examined in layer II pyramidal cells. Comparisons of currentvoltage relationships before and after development of the allor-none response component showed no consistent differences: a small increase in membrane resistance was observed in 1 cell, a small decrease in 2 cells, and no apparent change in 4 cells (Fig. 5). Comparison of the slope of the rising phase of the monosynaptic EPSP evoked by association or afferent fiber stimulation before and after establishment of the late potential also failed to reveal consistent changes that could underlie generation of the late potential: in 15 cells, the slope displayed small decreases $(n=11)$ or small increases $(n=4)$, with an overall average decrease of $7 \%$. In all cells tested $(n=10)$, the presence of both early, $\mathrm{Cl}^{-}$-mediated and late, $\mathrm{K}^{+}$-mediated IPSPs could be demonstrated after development of the late potential by injection of depolarizing current (Fig. $2 F$ ). While accurate quantitative comparisons of IPSPs before and after development of the late potential were difficult because of technical limitations, ${ }^{3}$ amplitudes and durations did not appear to change substantially for either IPSP after induction of the late response (compare $B$

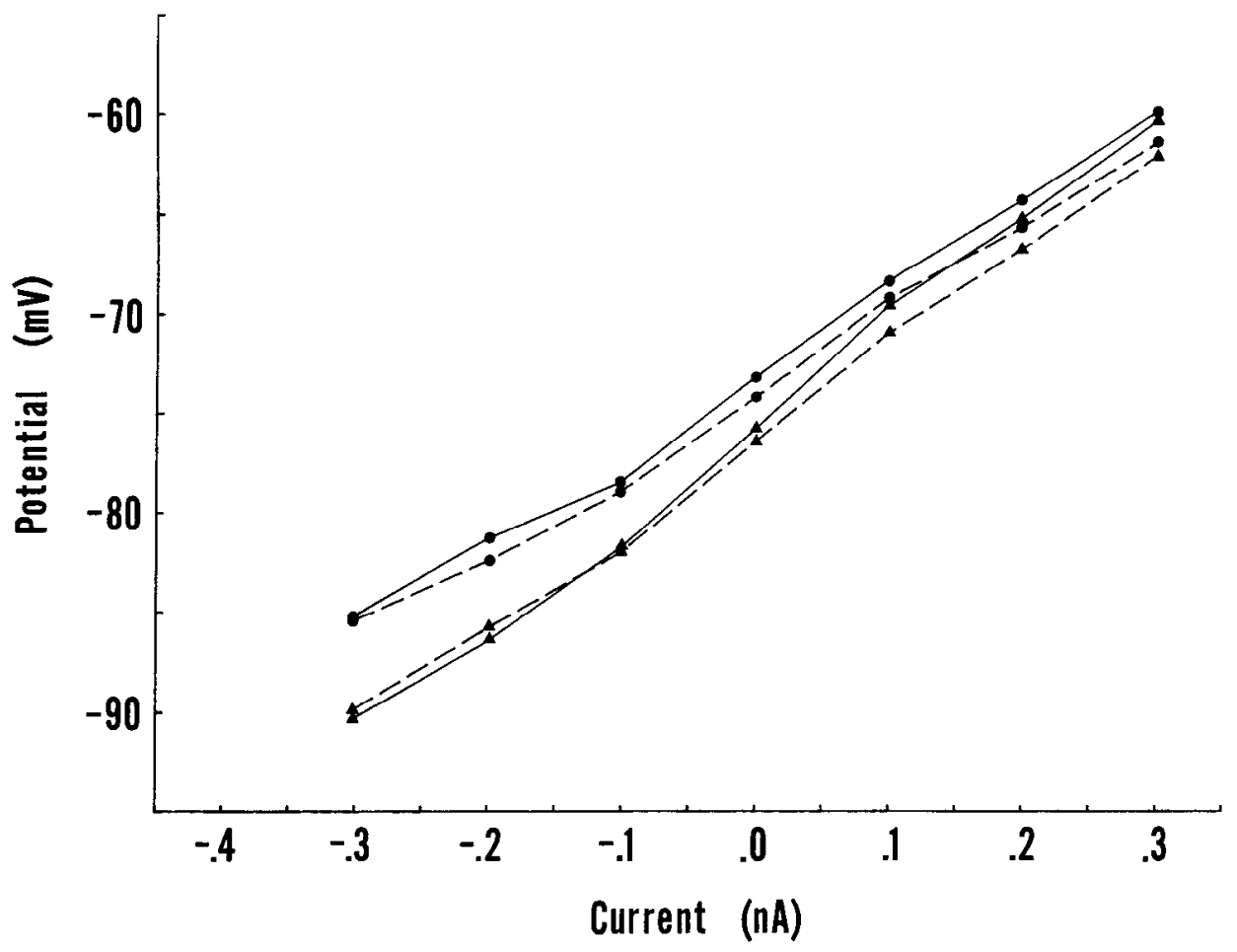

Figure 5. Current-voltage relationships for 2 cells (dots and triangles) beforc (solid lines) and after (dashed lines) bursting activity and establishment of the late depolarizing potential. Membrane potential was measured at a latency of approximiately $300 \mathrm{msec}$ after onset of square pulses of current injected through the recording micropipette. Bridge balance was verified for each step. In these and other cells, bursting activity had little effect on the current-voltage relationship. 


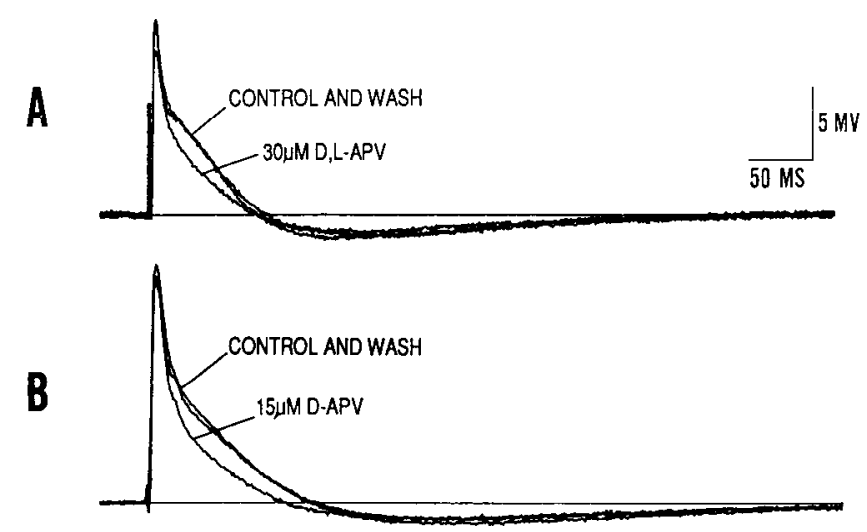

Figure 6. Efrects of APV on normal responses to association fiber stimulation. $A$, Superimposed responses of a cell in a normal slice before, during, and after addition of $30 \mu \mathrm{M} \mathrm{D}, \mathrm{L}-\mathrm{APV}$. $B$, Same as $A$, but different slice with $15 \mu \mathrm{M}$ D-APV. A positive-going inflection on the falling phase of the depolarizing potential was blocked or greatly reduced by both $D$ and D,L-APV.

and $F$ in Fig. 2). Determinations of $\mathrm{Na}^{+}$spike threshold were subject to the same technical limitations as IPSP amplitudes, but approximate values obtaincd using suprathrcshold afferent or association fiber stimulation ruled out substantial changes following induction of the late response. It appears unlikely, therefore, that the late potential results exclusively from changes in the membrane or response properties of layer II pyramidal cells or from changes in the strength of excitatory or inhibitory processes evoked by stimulation of association or afferent fibers.

\section{Effects of APV on changes induced by $0 \mathrm{Mg}^{2+}$}

It has been shown in other preparations that NMDA receptors play an important role in the induction of plastic changes in the CNS. To test for the involvement of NMDA receptors in the normal response to association fiber stimulation, and in the generation of the late depolarizing potential, the specific NMDA receptor antagonist APV was employed. The most obvious effect of APV on the normal response to association fiber stimulation was the blockage of a depolarizing inflection on the falling phase of the graded depolarization evoked by high-strength stimulation (Fig. 6). This effect was obtained over a wide concentration range of D,L-APV (10-100 $\mu \mathrm{M})$ and with $15 \mu \mathrm{M}$ D-APV $(n=16)$. The change in response waveform was not due to a decrease in membrane time constant since APV produced no change in input resistance $(n=3)$. In addition to blocking the depolarizing hump, D,L-APV at concentrations as low as $10 \mu \mathrm{M}$ reduced the rise-time of the monosynaptic EPSP. However, $15 \mu \mathrm{M}$ D-APV had little or no comparable effect, suggesting that the effect of $\mathrm{D}, \mathrm{L}-\mathrm{APV}$ on EPSP rise-time is largely the result of a nonspecific action of the $\mathrm{L}$-isomer, as previously reported for other systems (see Collingridge et al., 1982).

In all cells tested in 9 of 9 slices, the presence of $30 \mu \mathrm{M} \mathrm{D}, \mathrm{L}-$ APV or $15 \mu \mathrm{M}$ D-APV prevented the induction of bursting activity in $0 \mathrm{Mg}^{2+}$, as well as the subsequent development of a

\footnotetext{
${ }^{3}$ As a consequence of the long period of time (typically $1.5-2 \mathrm{hr}$ ) required for the recording of averaged control traces at a number of different shock strengths, stimulation in $0 \mathrm{Mg}^{2+}$, and stabilization after washout, small changes ( $1-5 \mathrm{mV}$ ) in apparent resting membrane potential occurred in most cells. Since IPSP amplitudes are a strong function of membrane potential and since it could not be determined if these changes in potential represent alterations in membrane potential or electrode tip potential, quantitative comparisons of IPSP amplitude were not attempted.
}

late depolarizing potential following return to normal $\Lambda \mathrm{CSF}$ (Fig. 7). ${ }^{4}$ In 1 slice, $10 \mu \mathrm{M} \mathrm{D,L-APV}$ failed to prevent bursting activity and late potentials developed, although in 4 other slices, 10-15 $\mu \mathrm{M}$ D,L-APV did prevent bursting activity and development of late potentials. The blockage by AP was reversible since bursting activity and late potentials developed in all slices after washout of APV, a second application of $0 \mathrm{Mg}^{2+}$, and a return to normal ACSF (Fig. 7, $E, F$ ).

Although D,L-APV at 10-30 $\mu \mathrm{M}$ blocked burst responses in 0 $\mathrm{Mg}^{2+}$ and development of the late depolarizing potential, concentrations of $10-100 \mu \mathrm{M}$ did not block this potential after it was established in the absence of APV $(n=7)$ (Fig. 8). Latency of the late potential, however, was consistently increased in APV. Decreases in amplitude of the late potential were observed in some cells, but such decreases were always comparable to those observed for the initial graded depolarizing response (Fig. 8). Membrane depolarization, which enhances NMDA response components by release of $\mathrm{Mg}^{2+}$ block (Nowak et al., 1984), failed to uncover a specific effect of APV on the established late potential. It appears, therefore, that NMDA receptor activation is not required for generation of the late depolarizing potential once it is established.

\section{Effects of ketamine}

All effects observed with APV, a competitive NMDA antagonist believed to act on receptors, were also obtained with ketamine, a specific, noncompetitive NMDA antagonist that may act on channels (Thomson et al., 1985; MacDonald et al., 1987). Ketamine at $10-15 \mu \mathrm{M}$ reversibly blocked the induction of bursting in $0 \mathrm{Mg}^{2+}(n=7)$, as well as the subsequent development of the late depolarizing potential following washout of $0 \mathrm{Mg}^{2+}$. However, ketamine at concentrations as high as $100 \mu \mathrm{M}$ failed to block the established late potential $(n=7)$, even after application of a large number of stimulation trials to promote its blocking action (MacDonald et al., 1987). Ketamine also blocked the APV-sensitive inflection on the falling phase of the depolarizing PSP in control responses.

\section{Changes induced by low $\mathrm{Cl}^{-}$and 4- $\mathrm{AP}$}

Interpretation of the findings with $0 \mathrm{Mg}^{2+}$ is complicated by the fact that bursting activity does not occur when NMDA receptors are blocked. Therefore, other manipulations of the bathing medium were employed to induce burst responses to fiber stimulation that continued after blockage of NMDA receptors. Both low $\mathrm{Cl}^{-}$and 4-AP were found to be effective for this purpose.

In low $\mathrm{Cl}^{-}$, burst responses to association fiber stimulation were consistently oblained (Fig. 9B), presumably because a reduction in extracellular $\mathrm{Cl}^{-}$converts the $\mathrm{Cl}^{-}$-mediated IPSP to an EPSP by moving the $\mathrm{Cl}^{-}$equilibrium potential positive to threshold (Tseng and Haberly, 1988a). Upon return to normal ACSF, late depolarizing potentials with all-or-none properties were recorded in all cells impaled in 15 of 16 slices (Fig. 9C). These depolarizing potentials closely resembled those induced by $0 \mathrm{Mg}^{2+}$, although in cells in 8 of 15 slices, threshold progressively increased or amplitude progressively decreased until they could no longer be evoked after periods of 6-97 min. Sta bility of the late potential appeared to be correlated with the

\footnotetext{
${ }^{4}$ While APV blocked the development of burst responses in $0 \mathrm{Mg}^{2+}$, there was, nevertheless, an increase in the duration of the initial depolarizing potential, even at a concentration of $30 \mu \mathrm{M}(185 \%$ increase at $10 \mu \mathrm{M}, n=3 ; 109 \%$ increase at 30 $\mu \mathrm{M}, n=3$; see Fig. 7C). This increase may represent incomplete blockage of NMDA receptors by APV.
} 


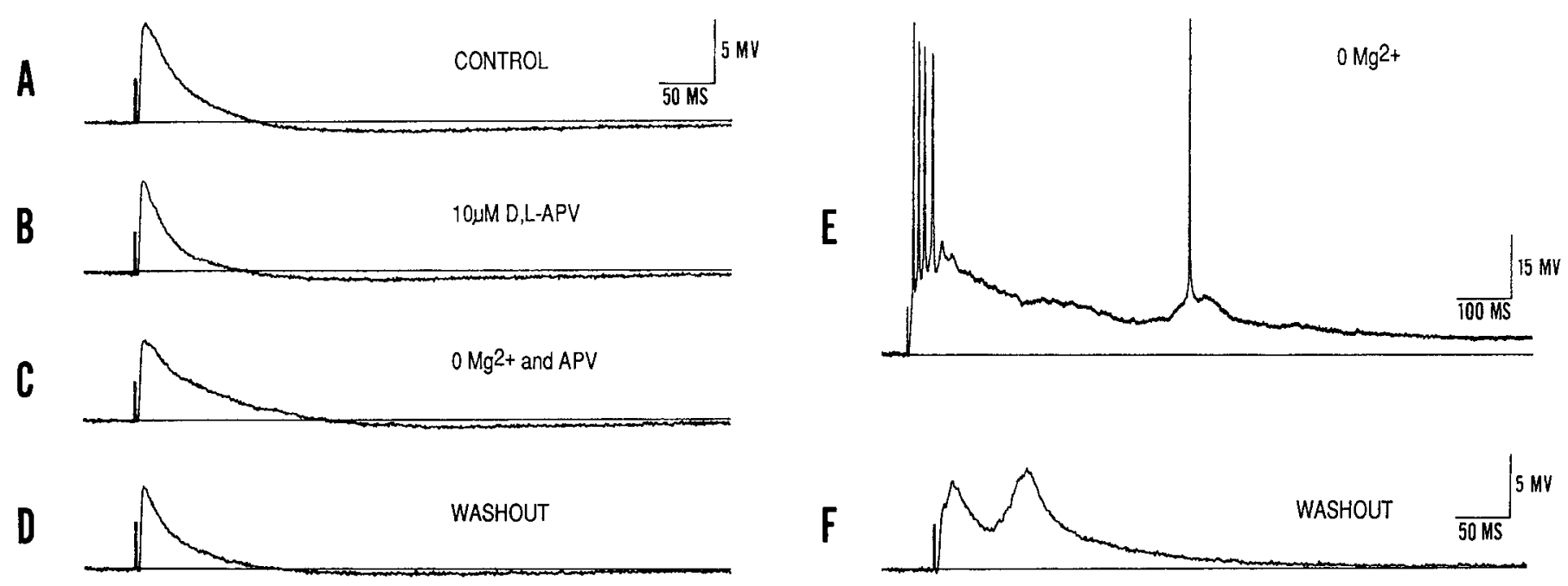

Figure 7. D,L-APV reversibly blocks development of burst responses to association fiber stimulation in $0 \mathrm{Mg}^{2+}$ and subsequent development of the late depolarizing potential following return to normal bathing medium. All records are from the same cell; shock strength was $6.0 \mathrm{~V}$ for response in $E$ and $3.0 \mathrm{~V}$ for all other responses. Traces $A-D$ are averages of 6 responses; $E$ and $F$ are single responses. $A$, Control response to association fiber stimulation in normal bathing medium. $B$, Response in $10 \mu \mathrm{M} \mathrm{D}, \mathrm{L}-\mathrm{APV}$. $C$, Response in $0 \mathrm{Mg}^{2+}$ with $10 \mu \mathrm{M}$ D,L-APV. APV blocked bursting in $0 \mathrm{Mg}^{2+}$, although a consistent increase in duration of the initial depolarizing potential was observed. $D$, Response following washout of $0 \mathrm{Mg}^{2+}$ and APV (recorded $3 \mathrm{hr}$ after control traces in $A$ ). $E$, Response after return to $0 \mathrm{Mg}^{2+}$ following washout of APV. $F$, Response in normal bathing medium after washout of the second application of $0 \mathrm{Mg}^{2+}$, demonstrating reversibility of the blocking action of APV. Scale bars in $A$ apply to all traces except $E$.

duration of exposure to low $\mathrm{Cl}^{-}$with a constant stimulation rate. Multiple applications of low $\mathrm{Cl}^{-}$increased the stability of the response in 3 of 5 slices.

In contrast to its effects on bursting induced by $0 \mathrm{Mg}^{2+}, 30$ $\mu_{\mathrm{M}} \mathrm{D}, \mathrm{L}-\Lambda \mathrm{PV}$ did not prevent burst responses to association fiber stimulation in low- $\mathrm{Cl}^{-} \mathrm{ACSF}$ (Fig. 9D). In all 7 slices examined, bursting activity in the presence of $30 \mu \mathrm{M} \mathrm{D}, \mathrm{L}-\mathrm{APV}$ failed to induce late potentials following a return to normal $\mathrm{Cl}^{-}$and subsequent washout of D,L-APV (Fig. 9E). As in the experiments with $0 \mathrm{Mg}^{2+}$, the blockage by APV was reversible, since a second treatment with low $\mathrm{Cl}^{-}$in the absence of APV did induce late potentials following washout.

Bursting activity induced by bath application of 20-100 $\mu \mathrm{M}$ 4-AP also resulted in the development of long-lasting, late depolarizing potentials that were retained following washout of 4-AP (all cells impaled in 17 of 17 slices) (Fig. 9, $F-I)$. D,L-APV at $30 \mu \mathrm{M}$ did not block bursting activity in 4-AP (Fig. $9 G)(n=$ 3 slices) but did block the development of consistent, stimulusevoked late potentials following washout of 4-AP (Fig. 9H). However, spontaneous all-or-none depolarizing potentials occurred at low frequency in all slices in $30 \mu \mathrm{M} \mathrm{D,L-APV}$ for 40 min or more after washout of 4-AP, and in 1 cell, such potentials were occasionally evoked by association fiber stimulation. Following washout of APV, the spontaneously occurring potentials became increasingly time-locked to stimulation until responses were indistinguishable from those induced in the absence of APV (Fig. 9I). This transition from spontaneous to stimulusevoked late depolarizing potentials was irreversible since reintroduction of APV did not reduce the degree of stimulus control.

\section{Discussion}

The primary observation reported here is that bursting activity induced by $0 \mathrm{Mg}^{2+}$, low $\mathrm{Cl}^{-}$, or 4-AP results, upon return to normal ACSF, in the development of a long-lasting, high-amplitude depolarizing potential that follows the normal graded postsynaptic potential in response to association or afferent fiber stimulation. This late potential occurs in an all-or-none fashion with a discrete threshold and has properties of an EPSP. Bath application of APV blocks development of this potential but does not block its occurrence once established.

A striking feature of the late potential is its stability over long periods of time. After induction in $0 \mathrm{Mg}^{2+}$, this potential usually lasted for the remainder of the experiment, typically $1-3 \mathrm{hr}$, with little change in average amplitude or threshold. While careful measurements of threshold over a period of several hours did reveal a small but progressive increase in threshold in some experiments (e.g., Table 1), such gradual increases may have been a consequence, at least in part, of a general decrease in slice excitability since in many cells the normal graded response decreased in amplitude by a small amount over comparable periods of time (e.g., compare $A$ and $D$ in Fig. 7).

\section{Synaptic nature of the late potential}

The nearly equivalent thresholds for the late potential in many cells in the same slice and the lack of effect of alterations in membrane potential of impaled cells on this threshold constitute

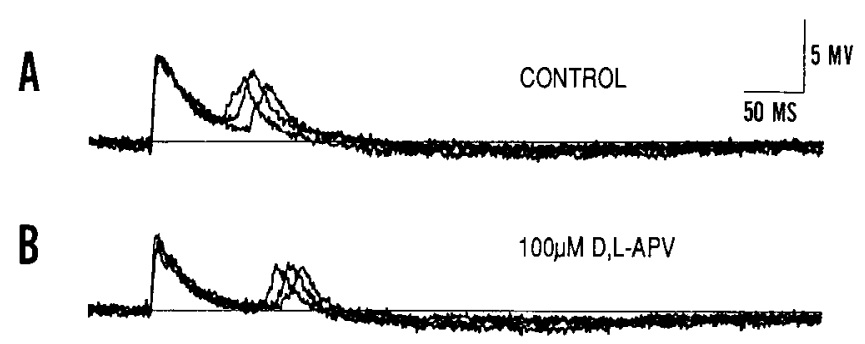

Figure 8. Effects of APV on responses to association fiber stimulation after induction of late depolarizing potentials by bursting activity in 0 $\mathrm{Mg}^{2+} . A$, Superimposed control responses from a cell in which late depolarizing potentials had been induced by bursting activity. $B, \mathrm{Re}$ sponses to the same stimulus as in $A$, but in the presence of $100 \mu \mathrm{M}$ D,L-APV. The late potential was not blocked, but latency was increased. 


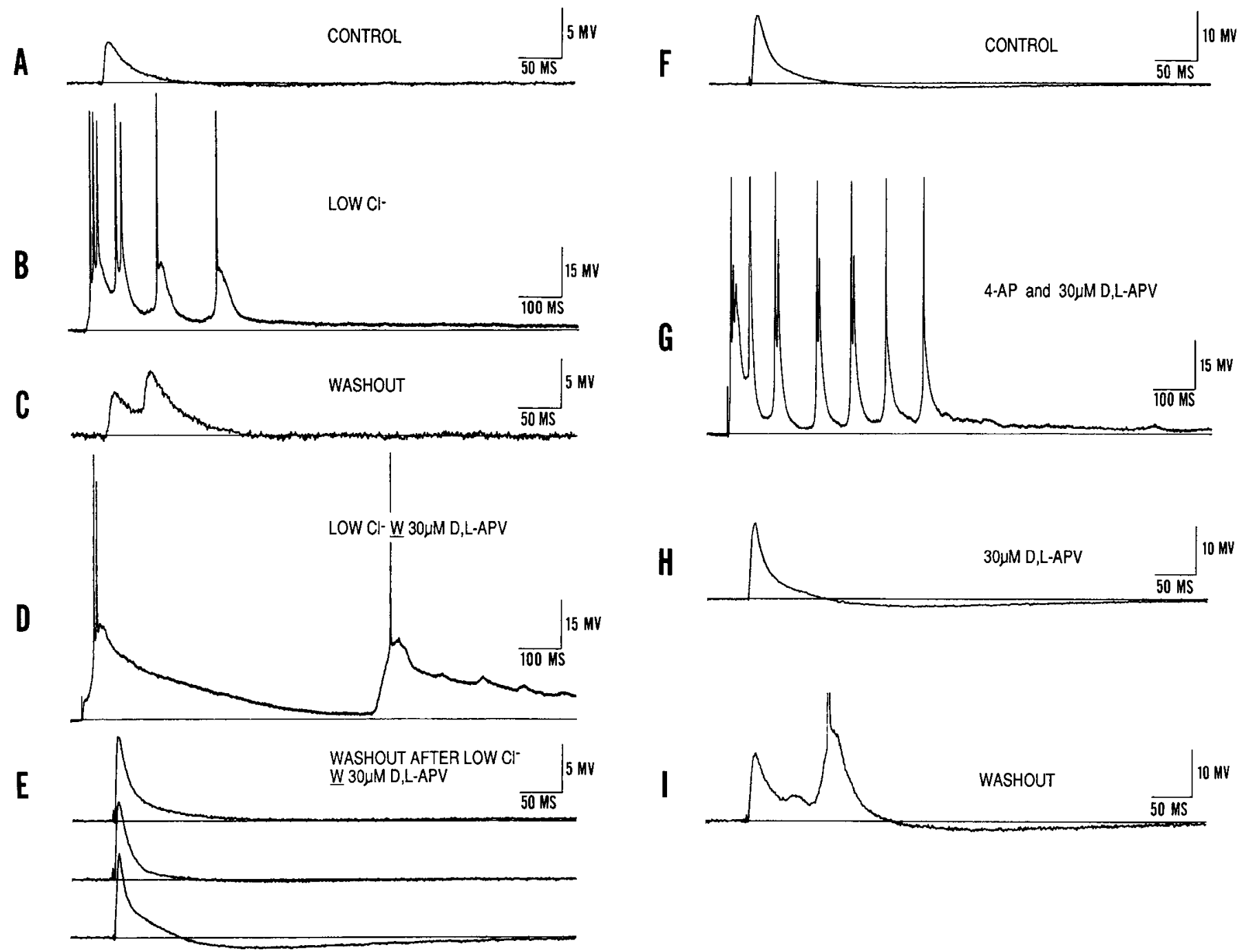

Figure 9. Burst responses and late depolarizing potentials induced by low $\mathrm{Cl}^{-}$and 4-AP, and the NMDA dependence of this induction. $A$, Control response to association fiber stimulation in normal bathing medium (average of 6 trials). $B$, Stimulus-induced bursting activity in bathing medium with $10 \%$ of normal $\mathrm{Cl}^{-} . C$. Response to the same stimulus as in $A$, following return to normal $\mathrm{Cl}^{-}$. Note the presence of a late depolarizing potential not present in the control response. As in the response after $0 \mathrm{Mg}^{2+}($ Fig. 2$)$, this potential occurred with a discrete threshold. $D$, Bursting activity elicited by low $\mathrm{Cl}^{-}(7 \%$ of normal concentration) in the presence of $30 \mu \mathrm{M}$ D,L-APV in a different slice than $A-C$. $E$, Responses to association fiber stimulation in cells from 3 different slices following bursting induced in the presence of $30 \mu \mathrm{M} \mathrm{D,L}$-APV by medium containing 7\% (top 2 traces) or $50 \%$ (bottom trace) of the normal $\mathrm{Cl}^{-}$concentration. Responses were recorded after washout of both low $\mathrm{Cl}^{-}$and $\mathrm{APV}$. The top trace was recorded from the same cell as in $D$. $F$, Control response to association fiber stimulation in normal bathing medium (average of 6 trials). $G$, Stimulusinduced bursting in $100 \mu \mathrm{M}$ 4-AP in the presence of $30 \mu \mathrm{M}$ D,L-APV. $H$, Response to the same stimulus as in $F$ in the presence of APV following washout of 4-AP. No stimulus-evoked late depolarizing potentials were observed while APV was present in the bath. $I$, Initial and late depolarizing potentials in response to the same stimulus as in $F$ and $H$ following washout of APV. A stimulus-evoked late depolarizing potential developed in this cell after removal of APV without a return to 4-AP medium (see text). Re-addition of APV (not illustrated) failed to block this potential.

strong evidence for generation by an interaction among large numbers of cells rather than an endogenous mechanism operating independently within individual cells. Given the presence of extensive intrinsic excitatory fiber systems in the pyriform cortex (Price, 1973; Haberly and Bower, 1984; Haberly and Presto, 1986), it can be postulated that the population synchrony is synaptically mediated via EPSPs. In the neocortex and hippocampal cortex it has been proposed that gap junctions also contribute to synchronous activity (Gutnick and Prince, 1981; Knowles et al., 1982), but a major role in generation of the present late depolarizing potential can probably be ruled out since dye coupling between pyramidal cells in the piriform cortex is comparatively rare, is usually confined to isolated cell pairs, and always occurs between distal dendrites of pyramidal cells (G.-F. Tseng and L. B. Haberly, unpublished observations). A significant synchronizing effect of field potentials as postulated for hippocampal cortex (Snow and Dudek, 1984) can also be ruled out on the basis of their very low amplitude in the present olfactory cortex slice preparation (typically $<300 \mu \mathrm{V}$ ), as well as the modeling study of Traub et al. (1987a).

\section{Role of $N M D A$ receptors}

A central issuc is whether NMDA reccptors play a direct role in the induction of the changes that underlie the late potential or if their action is indirect via a boosting of some aspect of bursting activity (see, for example, Herron et al., 1986). The 
experiments with low $\mathrm{Cl}^{-}$clearly established that APV can block induction of this potential even in the presence of bursting activity, suggesting a direct role for NMDA receptors. Nevertheless, an indirect role cannot be ruled out since activation of NMDA receptors could alter a component of bursting activity that is essential for the induction process. As a consequence of the complex nature of burst responses evoked in low $\mathrm{Cl}^{-}, 0$ $\mathrm{Mg}^{2+}$, and 4-AP, and the high degree of variability of these responses over time and in different slices, a systematic analysis of the effects of APV on bursting activity was not undertaken.

The findings with 4-AP were consistent with the primary conclusion that bursting activity induces long-lasting, stimulusevoked, late depolarizing potentials, but the effects of APV on generation of these potentials were more complex than in experiments with $0 \mathrm{Mg}^{2+}$ and low $\mathrm{Cl}^{-}$. On the basis of the present evidence it cannot be determined if the spontaneous all-or-none potentials that occurred in the presence of APV after 4-AP treatment were a consequence of a non-NMDA-dependent change in neuron response properties induced by 4-AP or if they resulted from incomplete washout of 4-AP. A lack of complete reversibility of the effects of 4-AP has been reported for other preparations (Lundh, 1978; Buckle and Haas, 1982), suggesting that the spontaneous potentials may be unrelated to the late depolarizing potential.

\section{Possible relationship to $L T P$ and kindling}

The late potential shares with long-term potentiation (LTP) in certain other systems a dependence on NMDA receptors for induction but lack of dependence once established (Harris et al., 1984; Wigström et al., 1986; Collingridge and Bliss, 1987; Errington et al., 1987). However, in contrast to LTP-boosted postsynaptic potentials, which retain their graded character, the late potential is evoked in an all-or-none fashion. Nevertheless, as postulated for epileptiform activity in the hippocampus (McNamara et al., 1980; Racine and Burnham, 1984), a graded LTP-like process could contribute to generation of the late allor-none potential. While no LTP of afferent and associational inputs to layer II pyramidal cells was detected, potentiation of other excitatory synapses in the piriform cortex could underlie generation of the late potential, as discussed below. This speculation is supported by the recent demonstration that shock trains like those that induce LTP of monosynaptic responses in the hippocampus, potentiate long-latency potentials in the piriform cortex in vivo (Stripling et al., 1988).

The present findings may also be related to the kindling phenomenon (Goddard et al., 1969; McNamara et al., 1980). Studies in the rat in vivo have revealed that kindling induces a highamplitude depolarizing potential in layer II pyramidal cells in the piriform cortex that resembles the present in vitro potential by virtue of an all-or-none occurrence, properties suggesting an underlying EPSP, a similar latency range, and great stability over time (Sutula and Haberly, 1986, and unpublished observations; also see Racine et al., 1983; Russell and Stripling, 1985). These parallels suggest that the present phenomenon is a possible in vitro model for kindling and epileptogenesis. The late potential also resembles responses obtained from slices taken from previously kindled animals (see Fig. 5, McIntyre and Wong, 1986), although interpretation of findings from this study is complicated by the fact that $4 \mathrm{mM} \mathrm{Mg}^{2+}$ was required in the bathing medium to prevent spontaneous and stimulus-evoked bursting activity by neurons in layer II in both control and experimental slices. Such bursting activity has never been observed in vivo (Haberly and Bower, 1984), or in the present in vitro preparation in slices through the same region studied by McIntyre and Wong (see Tseng and Haberly, 1988a).

\section{Relationship to findings from hippocampus}

The present findings for olfactory cortex are similar in certain respects to those obtained in slice preparations from the CA1 (Slater et al., 1985) and CA3 (Anderson et al., 1987) regions of the hippocampus. In these studies, bursting activity evoked by shock trains or NMDA application induced evoked and spontaneous epileptiform activity that lasted for up to several hours. High concentrations of D,L-APV (100-200 $\mu \mathrm{M})$ blocked development of the epileptiform activity but did not block it once established. However, the epileptiform activity in these studies was different in form from that observed in the present study (much longer duration with repetitive spiking), and in the study of Slater et al. (1985), the initial graded response to Schaeffer collateral stimulation increased substantially after bursting activity, prompting the hypothesis that LTP-like facilitation of inputs to pyramidal cells led to the epileptiform activity. In the present study no such facilitation was present in pyramidal cells in layer II (equivalent to stratum pyramidale of hippocampus).

\section{Possible mechanisms of generation}

Experimental and theoretical studies (Traub and Wong, 1983; Wong and Traub, 1983; Traub et al., 1985, 1987b; Rutecki et al., 1987) have provided evidence that long-latency, all-or-none EPSPs can be induced in systems in which reciprocal excitatory connections are present if the balance between excitatory and inhibitory processes is disturbed. These results, and the recent demonstration of an APV-sensitive reduction in the strength of both $\mathrm{Cl}^{-}$- and $\mathrm{K}^{+}$-mediated inhibition in hippocampal cortex as a consequence of tetanic stimulation (Stelzer et al., 1987; see also Miles and Wong, 1987), suggest that a decrease in the strength of inhibition could be involved in development of the late potential. While technical limitations precluded accurate quantitative comparisons, both $\mathrm{Cl}^{-}$- and $\mathrm{K}^{+}$-mediated IPSPs were clearly present and of substantial amplitude in layer II pyramidal cells after induction of the late potential. Nevertheless, since large decreases in amplitude of these processes could have occurred in cell populations that were not examined, and since even small decreases could facilitate generation of all-ornone responses, this mechanism cannot be ruled out as a contributing factor on the basis of the present evidence. However, it appears unlikely that a decrease in the strength of inhibitory processes acting on layer II pyramidal cells is solely responsible for generation of the late response.

In view of the extensive excitatory interconnections between layer II pyramidal cells in the piriform cortex via short and long fibers (Haberly and Behan, 1983; Haberly and Bower, 1984; Haberly and Presto, 1986), an increase in the strength of excitation with an insufficient compensatory increase in inhibition could also lead to all-or-none potentials via regenerative positive feedback within this cell population (Traub and Wong, 1983; Traub et al., 1985, 1987b; Wilson et al., 1986; Rutecki et al., 1987). However, the lack of a consistent increase in the strength of EPSPs evoked in pyramidal cells by stimulation of intrinsic association fibers following bursting activity, ${ }^{5}$ the lack of consistent changes in the $I-V$ relationship, and the lack of detectable changes in $\mathrm{Na}^{+}$spike threshold argue against this mechanism. 
In addition, the high threshold of $\mathrm{Na}^{+}$spikes in layer II pyramidal cells in vitro (Tseng and Haberly, 1988a) as well as in vivo (Haberly and Bower, 1984) appears to preclude a major contribution from positive feedback between layer II cells to generation of the all-or-none late response.

The evidence outlined above suggests that the fundamental change or changes that underlie development of the late potential occur primarily in neuron populations that are synaptically connected with layer II pyramidal cells rather than in the layer II pyramidal cells themselves. Recent anatomical and physiological studies indicate that pyramidal cells in layer II provide synaptic input to cells in the deep part of layer III and the underlying endopiriform nucleus and that local and ascending collaterals from these deep cells are present that could provide reciprocal connections and positive fecdback (Habcrly and Presto, 1986; Tseng and Haberly, 1987). Changes in excitatory or inhibitory processes in these deep cells could therefore underlie the late potential. Deep cells in normal slices (Tseng and Haberly, 1987, 1988b, and unpublished observations) have properties that could contribute to generation of the present longlatency, all-or-none response. These include a slow regenerative potential, lower $\mathrm{Na}^{+}$spike thresholds than layer II pyramidal cells, and long-latency EPSPs. The synchronization of such longlatency excitatory activity or the enhancement of reciprocal synaptic connections between superficial and deep layers following bursting activity, may be sufficient to generate a long-latency, all-or-none potential in layer II pyramidal cells. The observation that the deep layers of piriform cortex have a low threshold for induction of seizure activity by convulsant drugs (Piredda and Gale, 1985) is an additional indication that this alternative warrants consideration.

\section{References}

Anderson, W. W., D. V. Lewis, H. S. Swartzwelder, and W. A. Wilson (1986) Magnesium-free medium activates seizure-like events in the rat hippocampal slice. Brain Res. 398: 215-219.

Anderson, W. W., H. S. Swartzwelder, and W. A. Wilson (1987) The NMDA receptor antagonist 2-amino-5-phosphonovalerate blocks stimulus train-induced epileptogenesis but not epileptiform bursting in the rat hippocampal slice. J. Neurophysiol. 57: 1-21.

Bowcr, J. M., and L. B. Habcrly (1986) Facilitating and nonfacilitating synapses on pyramidal cells: A correlation between physiology and morphology. Proc. Natl. Acad. Sci. USA 83: 1115-1119.

Buckle, P. J., and H. L. Haas (1982) Enhancement of synaptic transmission by 4 -aminopyridine in hippocampal slices of the rat. J. Physiol. (Lond.) 326: 109-122.

Coan, E. J., and G. L. Collingridge (1985) Magnesium ions block an $\mathrm{N}$-methyl-D-aspartate receptor-mediated component of synaptic transmission in rat hippocampus. Neurosci. Lett. 53: 21-26.

Collingridge, G. L., and T. V. P. Bliss (1987) NMDA receptors-their role in long-term potentiation. Trends Neurosci. 10: 288-293.

Collingridge, G. L., S. J. Kehl, and H. McI.ennan (1982) The action of an N-methylaspartate antagonist on synaptic processes in the rat hippocampus. J. Physiol. (Lond.) 338: 27P.

Errington, M. L., M. A. Lynch, and T. V. P. Bliss (1987) Long-term potentiation in the dentate gyrus: Induction and increased glutamate release are blocked by D(-)aminophosphonovalerate. Neuroscience 20: 279-284.

Freeman, W. J., and W. Schneider (1982) Changes in spatial patterns

\footnotetext{
${ }^{5}$ Individual pyramidal cells in layer II of piriform cortex give rise to both local axon collaterals that synapse on basal dendrites of nearby pyramidal cells and long association fibers that synapse on apical dendrites in layer Ib (Haberly and Behan, 1983; Haberly and Presto, 1986). Stimulation in layer Ib would be expected to activate both long fibers and local collaterals via orthodromic and antidromic invasion. The results therefore indicate that efficacies of association fiber synapses on both apical and basal dendrites are not substantially altered by bursting activity.
}

of rabbit olfactory EEG with conditioning to odors. Psychophysiology 19: 44-56.

Goddard, G. V., D. C. McIntyre, and C. K. Leech (1969) A permanent change in brain function resulting from daily electrical stimulation. Exp. Neurol. 25: 295-330.

Grossberg, S. (1976) Adaptive pattern classification and universal recording: II. Feedback, expectation, olfaction, and illusions. Biol. $\mathrm{Cy}$ bernet. 23: 187-202.

Gutnick, M. J., and D. A. Prince (1981) Dye coupling and possible electronic coupling in the guinea pig neocortical slice. Science 211 : 67-70.

Haberly, L. B. (1985) Neuronal circuitry in olfactory cortex: Anatomy and functional implications. Chem. Senses 10: 219-238.

Haberly, L. B., and M. Behan (1983) Structure of the piriform cortex of the opossum. III. Ultrastructural characterization of synaptic terminals of association and olfactory bulb afferent fibers. J. Comp. Neurol. 219: 448-460.

Haberly, L. B., and J. M. Bower (1984) Analysis of association fiber system in piriform cortex with intracellular recording and staining techniques. J. Neurophysiol. 51: 90-112.

I Iaberly, L. B., and S. Presto (1986) Ultrastructural analysis of synaptic relationships of intracellularly stained pyramidal cell axons in piriform cortex. J. Comp. Neurol. 248: 464-474.

Harris, E. W., A. H. Ganong, and C. W. Cotman (1984) Long-term potentiation in the hippocampus involves activation of N-methyl-Daspartate receptors. Brain Res. 323: 132-137.

Herron, C. E., R. A. J. Lester, E. J. Coan, and G. L. Collingridge (1986) Frequency-dependent involvement of NMDA receptors in the hippocampus: A novel synaptic mechanism. Nature 322: 265-268.

Horne, A. L., N. L. Harrison, J. P. Turner, and M. A. Simmonds (1986) Spontaneous paroxysmal activity induced by zero magnesium and bicuculline: Suppression by NMDA antagonists and GABA mimetics. Eur. J. Pharmacol. 122: 231-238.

Kairiss, E. W., R. J. Racine, and G. K. Smith (1984) The development of the interictal spike during kindling in the rat. Brain Res. 322: 101110 .

Knowles, W. D., P. G. Funch, and P. A. Schwartzkroin (1982) Electronic and dye coupling in hippocampal CA1 pyramidal cells in vitro. Neuroscience 7: 1713-1722.

Lundh, H. (1978) Effects of 4-aminopyridine on neuromuscular transmission. Brain Res. 153: 307-318.

Lynch, G. (1986) Synapses, Circuits, and the Beginnings of Memory, pp. 25-57, MIT Press, Cambridge, MA.

MacDonald, J. F., Z. Miljkovic, and P. Pennefather (1987) Use-dependent block of excitatory amino acid currents in cultured neurons by ketamine. J. Neurophysiol. 58: 251-266.

McIntyre, D. C., and R. J. Racine (1986) Kindling mechanisms: Current progress on an experimental epilepsy model. Prog. Neurobiol. 27: $1-12$.

McIntyre, D. C., and R. K. S. Wong (1986) Cellular and synaptic properties of amygdala-kindled pyriform cortex in vitro. J. Neurophysiol. 55: 1295-1307.

McIntyre, D. C., D. Nathanson, and N. Edson (1982) A new model of partial status epilepticus based on kindling. Brain Res. 250: 5363.

McNamara, J. O., M. C. Byrne, R. M. Dasheiff, and J. G. Fitz (1980) The kindling model of epilepsy: A review. Prog. Neurobiol. 15: 139159.

Miles, R., and R. K. S. Wong (1987) Latent synaptic pathways revealed after tetanic stimulation in the hippocampus. Nature 329: 724-726.

Millan, M. H., S. Patel, L. M. Mello, and B. S. Meldrum (1986) Focal injection of 2-amino-7-phosphonoheptanoic acid into prepiriform cortex protects against pilocarpine-induced limbic seizures in rats. Neurosci. Lett. 70: 69-74.

Nowak, L., P. Bregestovski, P. Ascher, A. Herbet, and A. Prochiantz (1984) Magnesium gates glutamate-activated channels in mouse central neurones. Nature 307: 462-465.

Piredda, S., and K. Gale (1985) A crucial epileptogenic site in the deep prepiriform cortex. Nature 317: 623-625.

Price, J. L. (1973) An autoradiographic study of complementary laminar patterns of termination of afferent fibers to the olfactory cortex. J. Comp. Neurol. 150: 87-108.

Racine, R. J., and W. M. Burnham (1984) The kindling model. In Electrophysiology of Epilepsy, P. Schwartzkroin and H. Wheal, eds., pp. 153-171, Academic, London.

Racine, R. J., N. W. Milgram, and S. Hafner (1983) Long-term po- 
tentiation phenomena in the rat limbic forebrain. Brain Res. 260: 217-231.

Russell, R. D., and J. S. Stripling (1985) Effect of olfactory bulb kindling on evoked potentials in the pyriform cortex. Brain Res. 361: $61-69$.

Rutecki, P. A., F. J. Lebeda, and D. Johnston (1987) 4-Aminopyridine produces epileptiform activity in hippocampus and enhances synaptic excitation and inhibition. J. Neurophysiol. 57: 1911-1924.

Slater, N. T., A. Stelzer, and M. Galvan (1985) Kindling-like stimulus patterns induce epileptiform discharges in the guinea pig in vitro hippocampus. Neurosci. Lett. 60:25-31.

Snow, P. J., and F. E. Dudek (1984) Electrical fields directly contribute to action potential synchronization during convulsant-induced epileptiform bursts. Brain Res. 323: 114-118.

Stelzer, A., N. T. Slater, and G. ten Bruggencate (1987) Activation of NMDA receptors blocks GABAergic inhibition in an in vitro model of epilepsy. Nature 326: 698-701.

Stripling, J. S., D. K. Patneau, and C. A. Gramlich (1988) Selective long-term potentiation in the pyriform cortex. Brain Res. 441: 281291.

Sutula, T. P., and L. B. Haberly (1986) Long-lasting alteration of evoked activity in piriform cortex induced by kindling of olfactory bulb. Soc. Neurosci. Abstr. 12: 1126.

Teyler, T. J., and P. DiScenna (1987) Long-term potentiation. Annu. Rev. Neurosci. 10: 131-161.

Thomson, A. M., and D. C. West (1986) N-methylaspartate receptors mediate epileptiform activity evoked in some, but not all, conditions in rat neocortical slices. Neuroscience 19: 1161-1177.

Thomson, A. M., D. C. West, and D. Lodge (1985) An N-methylaspartate receptor-mediated synapse in rat cerebral cortex: A site of action of ketamine? Nature 313: 479-481.

Traub, R. D., and R. K. S. Wong (1983) Synchronized burst discharge in disinhibited hippocampal slice. II. Model of cellular mechanism. J. Neurophysiol. 49: 459-471.

Traub, R. D., R. K. S. Wong, R. Miles, and W. D. Knowles (1985)
Neuronal interactions during epileptic events in vitro. Fed. Proc. 44: 2953-2955.

Traub, R. D. W. D. Knowles, R. Miles, and R. K. S. Wong (1987a) Models of the cellular mechanism underlying propagation of epileptiform activity in the $\mathrm{CA} 2-\mathrm{CA} 3$ region of the hippocampal slice. Neuroscience 21: 457-470.

Traub, R. D., R. Miles, and R. K. S. Wong (1987b) Models of synchronized hippocampal bursts in the presence of inhibition. I. Single population events. J. Neurophysiol. 58: 739-751.

Tseng, G.-F., and L. B. Haberly (1987) Paired shocks induce a very high amplitude facilitation of late EPSPs in deep neurons in piriform cortex. Soc. Neurosci. Abstr. 13: 156.

Tseng, G.-F., and L. B. Haberly (1988a) Characterization of synaptically mediated fast and slow inhibitory processes in piriform cortex in an in vitro slice preparation. J. Neurophysiol. 59: 1352-1376.

Tseng, G.-F., and L. B. Haberly (1988b) A slow regenerative potential in cells in deep layers of rat piriform cortex. Soc. Neurosci. Abstr. 14: 278 .

Walther, H., J. D. C. Lambert, R. S. G. Jones, U. Heinemann, and B. Hamon (1986) Epileptiform activity in combined slices of the hippocampus, subiculum and entorhinal cortex during perfusion with low magnesium medium. Neurosci. Lett. 69: 156-161.

Wigström, H., B. Gustafsson, and Y.-Y. Huang (1986) Mode of action of excitatory amino acid receptor antagonists on hippocampal longlasting potentiation. Neuroscience 17: 1105-1115.

Wilson, M., and J. M. Bower (1987) A computer simulation of a threedimensional model of piriform cortex with functional implications for storage and recognition of spatial and temporal olfactory patterns. Soc. Neurosci. Abstr. 13: 1401.

Wilson, M., J. Bower, J. Chover, and L. Haberly (1986) A computer simulation of piriform cortex. Soc. Neurosci. Abstr. 12: 1358.

Wong, R. K. S., and R. D. Traub (1983) Synchronized burst discharge in disinhibited hippocampal slice. I. Initiation in CA2-CA3 region. J. Neurophysiol. 49: 442-458. 